\title{
Evaluating a Basic Assumption of Learning Trajectories: The Case of Early Patterning Learning
}

\author{
Arthur J. Baroody \\ University of Illinois at Urbana-Champaign, United States \\ Nursel Yilmaz \\ Middle East Technical University, Turkey \\ Douglas H. Clements \\ Julie Sarama \\ University of Denver, United States
}

Although hypothetical learning trajectories (HLTs) are often viewed as a valuable instructional tool, little research has directly evaluated their value. A basic assumption of HLTs is that ordering instructional activities by developmental difficulty enhances learning. A randomized control trial (RCT) served to evaluate this assumption with a hypothetical learning trajectory (HLT) for early patterning. The RCT $(n=16)$ entailed comparing two patterning interventions that involved the same activities, but only one ordered them based on an HLT. Each intervention involved twelve 15- to 20minute sessions. Quantitative data were collected from testing before and 2 weeks after the intervention sessions; qualitative data were collected during the instruction sessions. The former indicated that both interventions were significantly and substantively successful in promoting transfer in identifying the core unit of repeating patterns and extending such patterns. As predicted, a small effect size favored the HLT-Like intervention for core identification but not extending patterns. Training on core identification or extending patterns was significantly and substantially more successful with 4- than with 3-year-olds, especially those less than 3.75-years of age. Moreover, qualitative analyses revealed that translating patterns into letters was much easier than doing so into concrete formats and that the former can be introduced early in patterning instruction while the later may need to be postponed. Reasons why instructional ordering did have a stronger impact and implications for further HLT research are discussed.

Keywords: Young children, Patterning, Curriculum, Learning trajectories 
Mathematics is described as the "science of patterns" (Steen, 1990), and there is general recognition that patterning (e.g., the recognition, duplication, and extension of repeating patterns) should be a component of early mathematics education (Burgoyne, Witteveen, Tolan, Malone, \& Hulme, 2017; Kidd et al., 2014; Miller, Rittle-Johnson, Loehr, \& Fyfe, 2016; National Council of Teachers of Mathematics, 2000; NGA/CCSSO, 2010; Papic et al., 2011). A hypothetical learning trajectory (HLT) - a theoretically and empirically supported sequence of developmental levels and activities for promoting progress to each level-has been proposed for early patterning (Sarama \& Clements, 2009; see LearningTrajectories.org for the most up-todate version of the HLT). However, little research exists on the early teaching and learning of patterning, less research has directly assessed the efficacy of HLTs, and no research has focused on whether HLTs might facilitate patterning instruction with preschoolers (Frye et al., 2013). The main purpose of the present experiment was to rigorously evaluate a key assumption of an HLT approach by comparing the efficacy of patterning instruction based on an HLT with instruction involving the same activities but not ordered by the HLT.

\section{Background on HLTs}

As used in the present report, HLTs consist of three components: a goal, a developmental progression, and instructional activities (Maloney, Confrey, \& Nguyen, 2014; National Research Council, 2009; Sarama \& Clements, 2009; Simon, 1995). A goal is a target developmental level. Goals are based on the structure of mathematics, societal needs, and research on children's thinking about and learning of mathematics, and require input from experts in mathematics, mathematics education, educational policy, and developmental psychology (Clements, Sarama, \& DiBiase, 2004; Fuson, 2004; Wu, 2011). The developmental progression of an HLT is a sequence of increasingly sophisticated knowledge levels that lead to achievement of a mathematical goal. Theoretically, each level serves as a foundation for successful learning of subsequent levels. Instructional activities include curricular tasks and pedagogical strategies designed explicitly to promote the development of each level.

\section{The Purported Value of HLTS}

In theory, HLTs can highlight developmentally appropriate and important goals and help focus instructional efforts on them. Such tools can also underscore that teachers need to consider and build on what children already know, including the developmental prerequisites for targeted instruction. That is, HLTs spotlight the need to determine where children are developmentally, so that instruction can target children's learning needs with meaningful and effective learning tasks. For all these reasons and more, 
researchers, educators, and policy makers have recommended HLTs as a useful tool for teachers in helping them to understand, promote, and assess children's mathematical thinking and development (Baroody, 2016; Butterfield, Forrester, McCallum, \& Chinnapan, 2013; Frye et al., 2013; Sarama \& Clements 2009). For example, learning trajectories were a core construct in the National Research Council (2009) report on early mathematics education, and the notion of levels of thinking was a key first step in the writing of the Common Core State Standards-Mathematics (NGA/CCSSO, 2010).

\section{Existing Evidence}

Although HLTs are often recommended as an instructional tool (e.g., Clements \& Sarama, 2014; Maloney, Confrey, \& Nguyen, 2014; National Research Council, 2009; Sarama \& Clements, 2009), Lobato and Walters (2017) noted little research has directly and systematically evaluated the specific educational contributions of HLTs compared to non-HLT-based instruction or their theoretical assumptions. In their review of the research, Frye et al. (2013) concluded that, although considerable research has shown interventions that have HLTs as a component are efficacious in promoting numeracy, little research has examined the unique contribution of HLTs (Frye et al., 2013). For example, a preschool curriculum based on HLTs promoted numeracy significantly more than did business-as-usual instruction (effect size, 1.07) or an intervention organized by mathematical topics (effect size, .47; Clements \& Sarama, 2008). Although the HLT and topically based interventions were closely matched in terms of content and superior performance of the former might due to using a HLT, the two curricula had other differences (e.g., different activities and integrated versus discrete content) that might account for the performance difference.

One basic assumption of HLTs is that first teaching hypothesized prerequisite levels is more efficacious than the often-recommended approach of directly teaching to the target level. Several studies have found support for this assumption in the domains of shape composition and early addition (Clements and colleagues, 2019, 2020a, 2020b). Baroody, Clements, and Sarama (under review) found that teaching the conceptual prerequisite for the hypothesized cardinality concept underlying counting out a specified number of items was significantly and (as measured by effect size) substantially more efficacious than directly teaching the counting-out skill and its hypothesized conceptual basis. Another key assumption of HLTs is that ordering instructional activities by developmental difficulty enhances learning. The present study is the first to evaluate this assumption and first to evaluate the efficacy of HLTs in the domain of patterning.

\section{A Patterning HLT}

Summarized in Table 1 is a modified version of the HLT for initial 
patterning instruction proposed by Sarama and Clements (2009), in which more implicit and concrete levels of development provide a basis for more explicit and abstract levels.

Levels 1 and 2 are similar to the original HLT. Children initially may have an implicit or intuitive sensitivity to regularities and expectation based on them (Level 1). Children then take a step toward explicit knowledge of patterning by fixing, copying, or extending simple repeating patterns (Level 2). Unlike previous levels that entail attending to surface features (i.e., use of a visual-matching strategy), Levels 3 and 4 require attending to the underlying structure of a pattern (Collins \& Laski, 2015). Although these levels form a single level in Sarama and Clements' (2009) HLT (see also LearningTrajectories.org), translating a repeating pattern into a new media

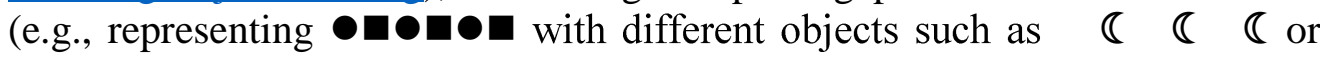
with different shapes such as $\downarrow$ ) and identifying its core (e.g., identifying as the smallest portion of the pattern that repeats) are distinct competencies and may not develop simultaneously (Rittle-Johnson, Fyfe, Loehr, \& Miller, 2015). Whereas the former requires implicit recognition of the core, the latter represents explicit knowledge of the repeating unit (RittleJohnson et al., 2015). For these reasons, translating a repeating pattern into a new media was designated a Level-3 competence and identifying its core, a Level-4 competence. Consistent with the designation of Levels $2 \mathrm{a}, 2 \mathrm{~b}, 3$, and 4 in Table 1, research indicates that most 4- and 5-year-olds can duplicate repeating patterns, many can extend them, some can translate them, and few can explicitly identify the core, respectively (Bennett \& Müller, 2010; Clements, Sarama, \& Lui, 2008; Rittle-Johnson et al., 2015; Rittle-Johnson, Fyfe, McLean, \& McEldoon, 2013).

In Workjobs, Baratta-Lorton (1972) recommended using letters to label, identify, and discuss repeating patterns. Labeling the elements of a pattern with letters (e.g., labeling both $\bigcirc \square \bigcirc \square \bigcirc \square$ and $\bullet ० \bullet ० ० ०$ as "ABABAB") might "help children see that patterns constructed of different materials ... share the same [underlying] structure"_-"a structure that transcends appearances" (Baroody, 1993, p. 2-84). Such labeling experiences, then, might be particularly helpful in promoting Level 3 (the patterngeneralizer level). Indeed, Fyfe, McNeil, and Rittle-Johnson (2015) adduced evidence that labeling the core of repeating patterns abstractly with letters is significantly more powerful than doing so concretely with physical characteristics such as color in fostering preschoolers' ability to recreate a model pattern using different materials (i.e., fostering pattern generalization). Using letters as a shorthand to label the core of a pattern may also draw explicit attention to the core or repeating unit of a repeating pattern and help children construct Level 4 (unit-patterner level).

\section{Hypothesis and Unresolved Issues}

Does patterning instruction in which activities are ordered according to 
an HLT result in greater learning than instruction involving the same activities but not so developmentally ordered? Specifically, the primary hypothesis is: For children at Level 1 or those who have only partially achieved Level 2 in Table 1, instruction that focuses first on Level 2 and then Levels 3 and 4 should produce better Level-4 (core-identification) learning than an intervention that blends the features of Level 4 with Levels 2 and 3. This is because children in the HLT intervention should have a greater opportunity to consolidate the developmental levels on which Level 4 builds, providing a sounder basis for learning to explicitly identify the core of new patterns. In contrast, the same will be not true for fostering the Level-2 competence of pattern extension, because both HLT and non-HLT participants will have the same basis for assimilating and benefitting from such instruction.

Might age be a factor in whether children benefit from coreidentification instruction? With a sample with a mean of 4.4 years $(\mathrm{SD}=0.4$, range 3.6 - 4.9), Fyfe et al. (2015) found that older children performed significantly better on a pattern-generalizer (Level-3) task. So, it seems reasonable to hypothesize that 4-year-olds should perform significantly better on what might be a more advanced core-identification (Level-4) task than 3year-olds, because the former are more developmentally ready.

Perhaps more importantly than age if the assumptions of an HLT approach are correct, initial developmental level should be a factor. Theoretically, patterning instruction on Levels 2 to 4 (especially if ordered) should better enable children who have initially achieved partial success with Level 2 to make better progress toward achieving Level 4 than peers who start at Level 1.

Another particularly important unresolved issue is: Where does labeling the elements of a pattern with letters (e.g., labeling $\bullet \mathbf{m e n}$ as "ABABAB") fit in a patterning HLT? Following Baratta-Lorton (1972), the Building Blocks Preschool Mathematics Curriculum (Clements \& Sarama, 2013) introduces using letters to label elements relatively early - with Level-2 activities. However, as letters constitute a different medium (and arguably an even more abstract one than different physical characteristics), it logically follows that translating a physical pattern into letters should be a Level-3 instructional activity (and, perhaps, one that is introduced after more concrete experiences that involving translating a pattern into different physical characteristics). On one hand, Fyfe et al.'s (2015) finding that labeling cores with letters was more efficacious than doing so with a physical characteristic in promoting pattern generalization (Level 3) is consistent with generally treating letters as an exceptional case and using them also with Level-2 activities (as in the Building Blocks Curriculum). On the other hand, it is unclear whether Fyfe et al.'s finding applies generally-also applies to using letters to label elements (as opposed to cores) and earlier Level-2 instruction. In other words, it unclear whether Level-2 children would find translating physical patterns into letters helpful or confusing. To explore the issue, the 
HLT condition included labeling the elements of a pattern as Level-3 activity, whereas the non-HLT condition included it as a Level-2 activity.

\section{Methods}

\section{Participants}

A total of 16 preschoolers ( 3 years- 3 months to $4-11$; median $=4$ year0.5 months) completed the study. Participants were drawn from three classes in a university preschool serving university faculty, staff, and students and a working-class community of a medium-size U.S. Mid-western city. Parental consent forms were received for 26 students of 58 sent out. One child refused to participate and was not pretested. Four children were excluded from the study because they were untestable at pretest due to a lack attentiveness. Three children were excluded because they were developmentally too advanced (i.e., had already achieved success with Level 2 in Table 1). One HLT intervention student moved before beginning training. One non-HLT student refused to continue after two training sessions. The experimental HLT-based group had four 3-year-olds, median age of 3-years and 11.5 months; five girls; 2 Caucasian, 4 Asian-American, 2 Latino/a; 2 free lunch. The non-HLT comparison group had three 3-year-olds, median age of 4-years and 1.5 months; four girls; 4 Caucasian, 3 Asian-American, 1 Latino/a; 2 free lunch.

\section{Interventions}

The key elements of the two interventions (summarized in Table 2) are based on the guidelines outlined in the Building Blocks Preschool Mathematics Curriculum (Clements \& Sarama, 2013). Both interventions focused on $\mathrm{AB}, \mathrm{ABB}$, and $\mathrm{ABC}$ patterns. Both started with labeling the elements of repeating patterns with physical characteristics and then with letters (e.g., labeling $\bullet \mathbf{0 \square \bullet}$ "Circle-square, circle-square, circle-square" and then "ABABAB"). Both interventions used "AND" to implicitly underscore the core of repeating pattern (e.g., labeling $\mathbf{0 0 \mathbf { 0 }}$ "Circle, square, AND circle, square, AND circle, square"), and using letters to label

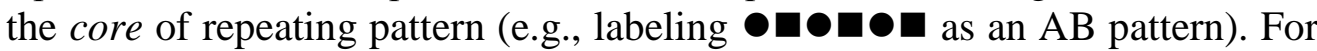
both interventions, the transition between using letters to label the elements of a pattern and to identify the core of a pattern entailed asking a child to first label the elements with letters and then identify the core-the smallest part that repeats- using letters.

Both interventions consisted of 12 sessions of 15 to 30 minutes each and the same activities. However, as indicated by Table 2 and illustrated by Figures 1 and 2, the activities were presented in different orders. The experimental intervention embodied the developmental order of the HLT described in Table 1: Level 2a, 2b, and 2c (two sessions each); then Level 3 (two sessions), and finally Level 4 (last four sessions). As the goal of the 
study was to rigorously test the assumption that order of instruction is critical (i.e., to control for other factors such as testing or dosage effects), the normal practices of an HLT approach such as using formative assessment to guide graduation to a new sublevel or level were not observed. For this reason, the experimental condition will henceforth be described as the HLT-Like intervention. In contrast to the experimental intervention where the target instruction of identifying the core explicitly using letters (Level 4) did not occur until Sessions 9 to 12 (after completing all Level-2 and -3 activities), the comparison intervention (a non-HLT approach) introduced the Level-4 target instruction almost immediately in Session 3 (amid Level-2 and -3 activities). The training materials consisted of manual games and activities adapted from the Building Blocks Preschool Mathematics Curriculum (Clements \& Sarama, 2013). An intervention was administered to children individually by two trainers (the second author and a female academic professional) in a room close to a child's preschool classroom. To minimize a teacher effect, trainers randomly chose children from each intervention group for each session.

Fidelity was ensured in several ways. Trainers were extensively tutored by the first author, including a 2-hour staff training session focused on the HLT summarized in Table 1, the rationale for each intervention, possible advantages and disadvantages of each intervention (e.g., building on prior, more easily understood knowledge may better foster learning versus focusing on identifying a core early may facilitate learning "more basic skills" such as fixing or extending a pattern), and an overview of how each intervention would be implemented (including the key differences of each intervention). A protocol, which included scripts for the introduction of each activity, were made up for each lesson of both interventions (see sample scripts in Figures 1 and 2). Two-hour weekly meetings focused on the rationale and implementation of the lesson plans (including the lesson protocols/scripts) for each intervention and the preparation and use of the specific materials needed for each intervention for the following week. A log for each intervention was kept to ensure every child received his or her correct intervention and received all lessons of an intervention. For the first third of the training, the two trainers worked together to administer the interventions to ensure a protocol/script was followed. The second author kept field notes of the training and consulted with the first author if questions arose about an intervention. The previous week's training efforts were discussed in the weekly meetings. These discussions included the trainers' observations about whether a lesson was effective and what adjustments might need to be made in future, similar activities. 


\section{Table 1}

\section{A Modified Version of the HLT for Initial Patterning Instruction}

\begin{tabular}{|c|c|}
\hline Levels of HLT & Explanation \\
\hline $\begin{array}{l}\text { Level 1: } \\
\text { Intuitive Patterner }\end{array}$ & $\begin{array}{l}\text { Implicitly detect simple repeating patterns and may even use them but may not recognize } \\
\text { patterns explicitly or accurately (e.g., "I'm wearing a pattern" when wearing a striped } \\
\text { shirt of two alternating colors or a multicolored shirt with no repeating pattern). }\end{array}$ \\
\hline $\begin{array}{l}\text { Level 2: } \\
\text { Perceptual Patterner }\end{array}$ & 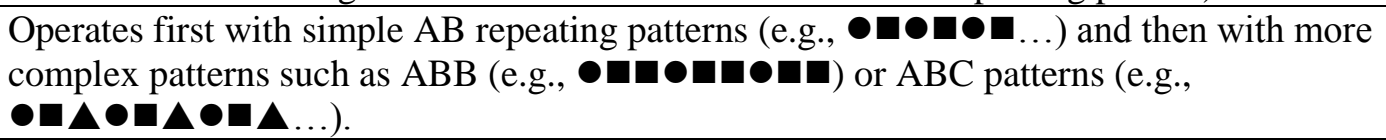 \\
\hline $\begin{array}{l}\text { Sublevel 2a: } \\
\text { AB Pattern Fixer } \\
\text { and Duplicator }\end{array}$ & $\begin{array}{l}\text { Can find the missing element of an } \mathrm{AB} \text { pattern and fix it (e.g., given } \mathbf{0} \mathbf{\square} \mathbf{\square} \text { _or } \\
\text { circle, square, circle, square, circle.... }\end{array}$ \\
\hline $\begin{array}{l}\text { Sublevel } 2 b: \\
\text { AB Pattern } \\
\text { Extender }\end{array}$ & $\begin{array}{l}\text { Can continue an } \mathrm{AB} \text { pattern (e.g., given square, circle, square, circle, square, circle, adds } \\
\text { on a square and circle and another square and circle). }\end{array}$ \\
\hline $\begin{array}{l}\text { Sublevel } 2 c: \\
\text { More complex pattern } \\
\text { Fixer and Extender }\end{array}$ & $\begin{array}{l}\text { Can fix, duplicate, and extend more complex repeating patterns such as } \mathrm{ABB} \text { and } \mathrm{ABC} \\
\text { patterns. }\end{array}$ \\
\hline $\begin{array}{l}\text { Level 3: } \\
\text { Generalized Patterner }\end{array}$ & $\begin{array}{l}\text { Can abstract a pattern and translate it into new media (e.g., given a repeating pattern such } \\
\text { as } \\
\text { red, blue, red, blue, red, blue), or the letters ABABAB. }\end{array}$ \\
\hline $\begin{array}{l}\text { Level 4: } \\
\text { Unit Patterner }\end{array}$ & $\begin{array}{l}\text { Can identify the core of a repeating pattern (the smallest portion of the pattern that repeats } \\
\text { to create the rest of the pattern). }\end{array}$ \\
\hline
\end{tabular}




\section{Table 2}

\section{How the Two Interventions Differed in the Timing of Their Common Elements (indicated by red bold type)}

\begin{tabular}{|c|c|c|c|c|c|c|c|c|c|c|}
\hline \multicolumn{6}{|c|}{ HLT-Like Intervention } & \multicolumn{5}{|c|}{ Non-HLT Intervention } \\
\hline $\begin{array}{l}\text { HLT Level } \\
\text { (adapted from } \\
\text { Sarama \& } \\
\text { Clements, 2009) }\end{array}$ & Session & $\begin{array}{l}\text { Physical } \\
\text { labels } \rightarrow \\
\text { elements }\end{array}$ & $\begin{array}{l}\text { Letters } \\
\stackrel{\rightarrow}{\rightarrow} \\
\text { elements }\end{array}$ & $\begin{array}{l}\text { Use of } \\
\text { "AND" }\end{array}$ & $\begin{array}{c}\text { Letters } \\
\rightarrow \\
\text { core }\end{array}$ & Session & $\begin{array}{l}\text { Physical } \\
\text { labels } \rightarrow \\
\text { elements }\end{array}$ & $\begin{array}{l}\text { Letters } \\
\stackrel{\rightarrow}{\text { elements }}\end{array}$ & $\begin{array}{l}\text { Use of } \\
\text { "AND" }\end{array}$ & $\begin{array}{c}\text { Letters } \\
\rightarrow \\
\text { core }\end{array}$ \\
\hline \multirow{2}{*}{$\begin{array}{l}\text { 2a. AB Pattern } \\
\text { fixer \& duplicator }\end{array}$} & 1 & $X$ & & & & 1 & $\mathrm{X}$ & $\mathbf{X}$ & $\mathbf{X}$ & \\
\hline & 2 & $\mathrm{X}$ & & & & 2 & $\mathrm{X}$ & $\mathbf{X}$ & $\mathbf{X}$ & \\
\hline \multirow{2}{*}{ 2b. AB Extender } & 3 & $\mathrm{X}$ & & & & 3 & $\mathrm{X}$ & $\mathbf{X}$ & $\mathbf{X}$ & $\mathrm{X}$ \\
\hline & 4 & $\mathrm{X}$ & & & & 4 & $\mathrm{X}$ & $\mathbf{X}$ & $\mathbf{X}$ & $\mathrm{X}$ \\
\hline $\begin{array}{l}\text { 2c ABB fixer, } \\
\text { duplicator } \& \\
\text { extender }\end{array}$ & 5 & $\mathrm{X}$ & & & & 5 & $\mathrm{X}$ & $\mathbf{X}$ & $\mathbf{X}$ & $\mathrm{X}$ \\
\hline $\begin{array}{l}\text { 2c ABC fixer, } \\
\text { duplicator \& } \\
\text { extender }\end{array}$ & 6 & $\mathrm{X}$ & & & & 6 & $X$ & $\mathbf{X}$ & $\mathbf{X}$ & $\mathrm{X}$ \\
\hline \multirow{2}{*}{$\begin{array}{l}\text { 3. Pattern } \\
\text { generalizer }\end{array}$} & 7 & $\mathrm{X}$ & $\mathrm{X}$ & $\mathrm{X}$ & & 7 & $\mathrm{X}$ & $\mathrm{X}$ & $\mathrm{X}$ & $\mathrm{X}$ \\
\hline & 8 & $\mathrm{X}$ & $\mathrm{X}$ & $\mathrm{X}$ & & 8 & $X$ & $X$ & $X$ & $\mathrm{X}$ \\
\hline \multirow{4}{*}{ 4. Core unit } & 9 & $X$ & $\mathrm{X}$ & $X$ & $X$ & 9 & $X$ & & $X$ & $X$ \\
\hline & 10 & $\mathrm{X}$ & $\mathrm{X}$ & $X$ & $X$ & 10 & $X$ & & $X$ & $\mathrm{X}$ \\
\hline & 11 & & & & $\mathrm{X}$ & 11 & & & & $\mathrm{X}$ \\
\hline & 12 & & & & $\mathrm{X}$ & 12 & & & & $\mathrm{X}$ \\
\hline
\end{tabular}

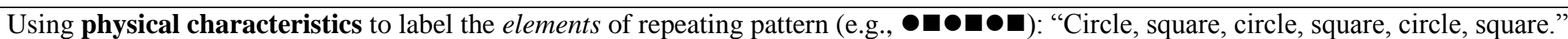

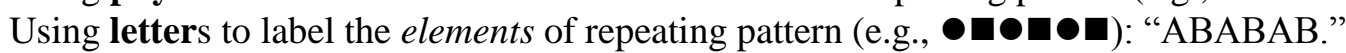

Using "AND" to implicitly underscore the core of repeating pattern (e.g., $\mathbf{\bullet} \mathbf{0} \mathbf{0} \mathbf{0})$ : "Circle, square AND circle, square AND circle, square."

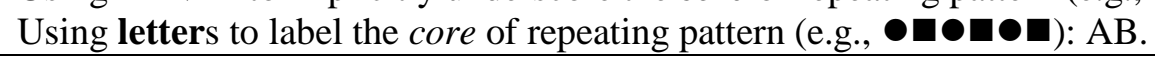




\begin{tabular}{|c|c|}
\hline HLT-Like Intervention & Non-HLT Intervention \\
\hline \multicolumn{2}{|c|}{$\begin{array}{l}\text { What's Missing? } \\
\text { Aim: Fill in missing element of a repeating AB pattern. }\end{array}$} \\
\hline $\begin{array}{l}\text { Example 1. Show geometric repeating pattern } \\
\text { below and encourage child to chant with you: } \\
\text { "circle, square, circle, square, circle, square." } \\
\text { Then, point to the blank in the pattern and say, } \\
\text { "This where a shape fell off"." Encourage child } \\
\text { to fix the pattern by saying: "Would you fix the } \\
\text { pattern?" }\end{array}$ & $\begin{array}{l}\text { Additional aims: Then extend the pattern. Introduce letters to } \\
\text { label (abstractly) the elements of the pattern. } \\
\text { Example 1. Show geometric repeating pattern below and encourage } \\
\text { child to chant with you: "circle-square AND circle-square AND } \\
\text { circle-square." } \\
\text { Emphasize the 'AND'. (The idea of a core is implicitly } \\
\text { introduced by labeling the elements of a pattern in core chunks } \\
\text { such as circle-square, AND circle-square, AND circle-square... } \\
\text { while emphasizing the 'AND'.) } \\
\text { Then, point to the blank in the pattern and say, "This where a shape } \\
\text { fell off'." Encourage child to fix the pattern by saying: "Would you } \\
\text { fix the pattern?" } \\
\text { After fixing the pattern, ask the child to EXTEND the pattern } \\
\text { by saying: "What should come next?" } \\
\text { Finally, give the child plastic letters A, B, and C and ask the } \\
\text { child to use letters to duplicate the pattern. } \\
\text { Prompt: Say: "Let's make this same pattern but with letters." } \\
\text { Summarize the labels the elements of the pattern: "So we can } \\
\text { call this pattern with small then large blocks an A-B AND A-B, } \\
\text { AND A-B pattern. } \\
\text { Example 2. }\end{array}$ \\
\hline Aim: Duplicate $A B$ patterns. & Can You Copy Me? \\
\hline $\begin{array}{l}\text { Ask the child to describe (e.g., "big, small, big, } \\
\text { small, big, small"). Help as needed. } \\
\text { Summarize the pattern: "So our pattern is small, } \\
\text { big, small, big, small, big, small, big." Then, ask } \\
\text { the child to copy the pattern with same materials } \\
\text { but of different colors. }\end{array}$ & $\begin{array}{l}\text { Additional aims: Translate AB patterns into letters (re- } \\
\text { represent the physical elements of an AB with letters). } \\
\text { Example 1. Show a strip of cubes. } \\
\text { Ask the child to describe (e.g., "small-big AND small-big AND } \\
\text { small-big "). Help as needed. Summarize the pattern: "So our } \\
\text { pattern is small, big, AND small, big, AND small, big, AND small, } \\
\text { big." Then, ask the child to copy the pattern with same materials but } \\
\text { of different colors. } \\
\text { Finally, provide plastic letters A, B, and C and ask the child to } \\
\text { use letters to duplicate the pattern. } \\
\text { Encourage the child to label the elements of the pattern: So we } \\
\text { can call this pattern with small then large blocks an A-B AND } \\
\text { A-B AND A-B pattern. }\end{array}$ \\
\hline
\end{tabular}

Figure 1. Partial plans for Session 1 HLT-Like and non-HLT Training illustrating how the interventions differed (indicated by red bold type). 


\begin{tabular}{|c|c|c|c|}
\hline \multirow[b]{2}{*}{ Level } & \multicolumn{2}{|c|}{ Session } & \multirow[b]{2}{*}{ Activity } \\
\hline & $\begin{array}{l}\text { LT- } \\
\text { Like }\end{array}$ & $\begin{array}{c}\text { Non- } \\
\text { LT }\end{array}$ & \\
\hline \multirow[t]{2}{*}{$2 b$} & \multirow[t]{2}{*}{4} & \multirow[t]{2}{*}{7} & $\begin{array}{l}\text { What Comes Next? } \\
\text { Aim: Extend a pattern strip with three complete cores } \\
\text { Procedure: For the first example, have child cover eyes and create the display shown below } \\
\text { (cups cover } 6 \text { additional bears in an AB pattern): }\end{array}$ \\
\hline & & & $\begin{array}{l}\text { Prompt: "The first thing you need to do is look at the part of my pattern that you can see. Then, } \\
\text { try to figure out what color bears are underneath my cups. } \\
\text { Touch the first cup and ask, "What do you think is under this cup? Why?" } \\
\text { Discuss the guess and then reveal the bear under the cup. If correct, remove the cup and prompt: } \\
\text { "How can you figure out which color comes next?" If incorrect, provide a hint: "Can you say the } \\
\text { pattern to yourself up to the next missing one?" If still incorrect, say: "Let's go through the } \\
\text { pattern together. Blue, red, blue, red, blue, red." Revealing the hidden bear and say, "Blue!" } \\
\text { Continue process until all the bears in your pattern are revealed. }\end{array}$ \\
\hline $2 \mathrm{c}$ & 5 & 8 & $\begin{array}{l}\text { Can You Make Your (ABB) Pattern Bigger? } \\
\text { Aim: Extend ABB patterns. } \\
\text { Procedure: Show an ABB pattern strip such as circle, star, star, circle, star, star, circle, star, } \\
\text { star). Say, "In this game, you try to copy my pattern with same materials and then make it bigger } \\
\text { by "keep going" with the pattern." } \\
\text { Discuss how they knew how to do so and wait for their response. }\end{array}$ \\
\hline 3 & 7 & 10 & \multirow{2}{*}{$\begin{array}{l}\text { How Different Is Your Pattern? } \\
\text { Aim: Foster pattern generalization by copying an } \mathrm{AB}, \mathrm{ABB}, \mathrm{ABC} \text { with different media (letters } \\
\text { and materials). Introduce using letters to abstractly label the elements of a pattern. The idea of a } \\
\text { core is implicitly introduced by labeling the elements of a pattern in core chunks (e.g., circle- } \\
\text { square, AND circle-square, AND circle-square. . while emphasizing the 'AND'). } \\
\text { Procedure: Show a geometric pattern strip and, for example, chant: Circle-square, AND circle- } \\
\text { square, AND circle-square). } \\
\text { Then, ask child to copy the given pattern with different materials put BELOW the circle-square } \\
\text { pattern. } \\
\text { Prompt: Present a different color circles, squares, triangles, and hexagons and say, "Let's make } \\
\text { this same pattern but with different materials." } \\
\text { Finally, give the child plastic letters A, B, C, and D (put ABOVE the green circle-square } \\
\text { pattern). }\end{array}$} \\
\hline & & & \\
\hline
\end{tabular}

Figure 2. Sample extension, pattern generalization, and core-identification activities. 
Figure 2 continued

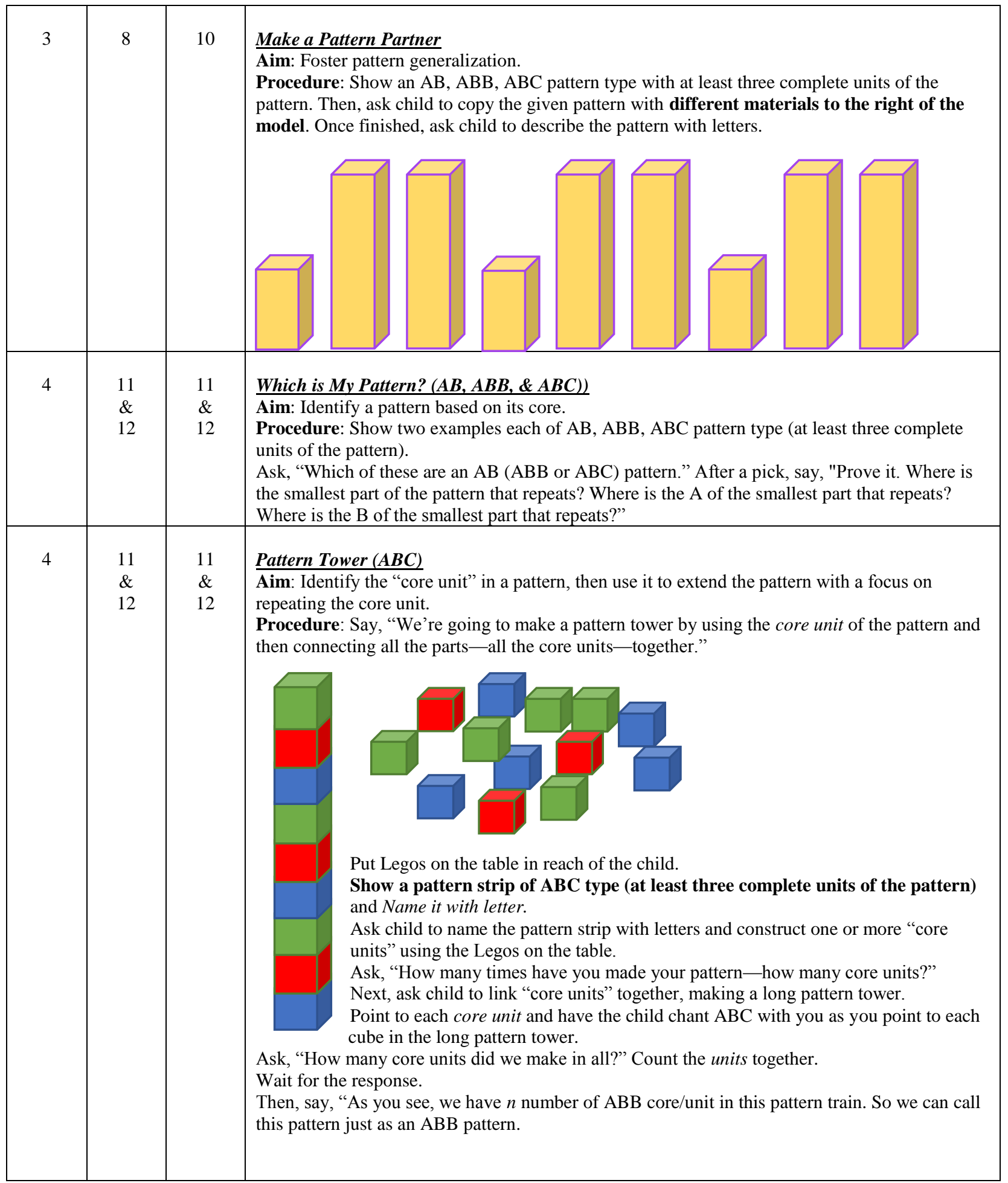

\section{Measures}

The pretest and posttest involved two tasks. The primary task involved 
identifying the core of patterns. A secondary, pattern-extension task was presented first. For both tasks, children were shown, in turn, AAB, ABCC, and $\mathrm{ABCD}$ patterns constructed of interlocking blocks (see Figure 3). Each example of a pattern included three complete core units and consist of 12 elements.

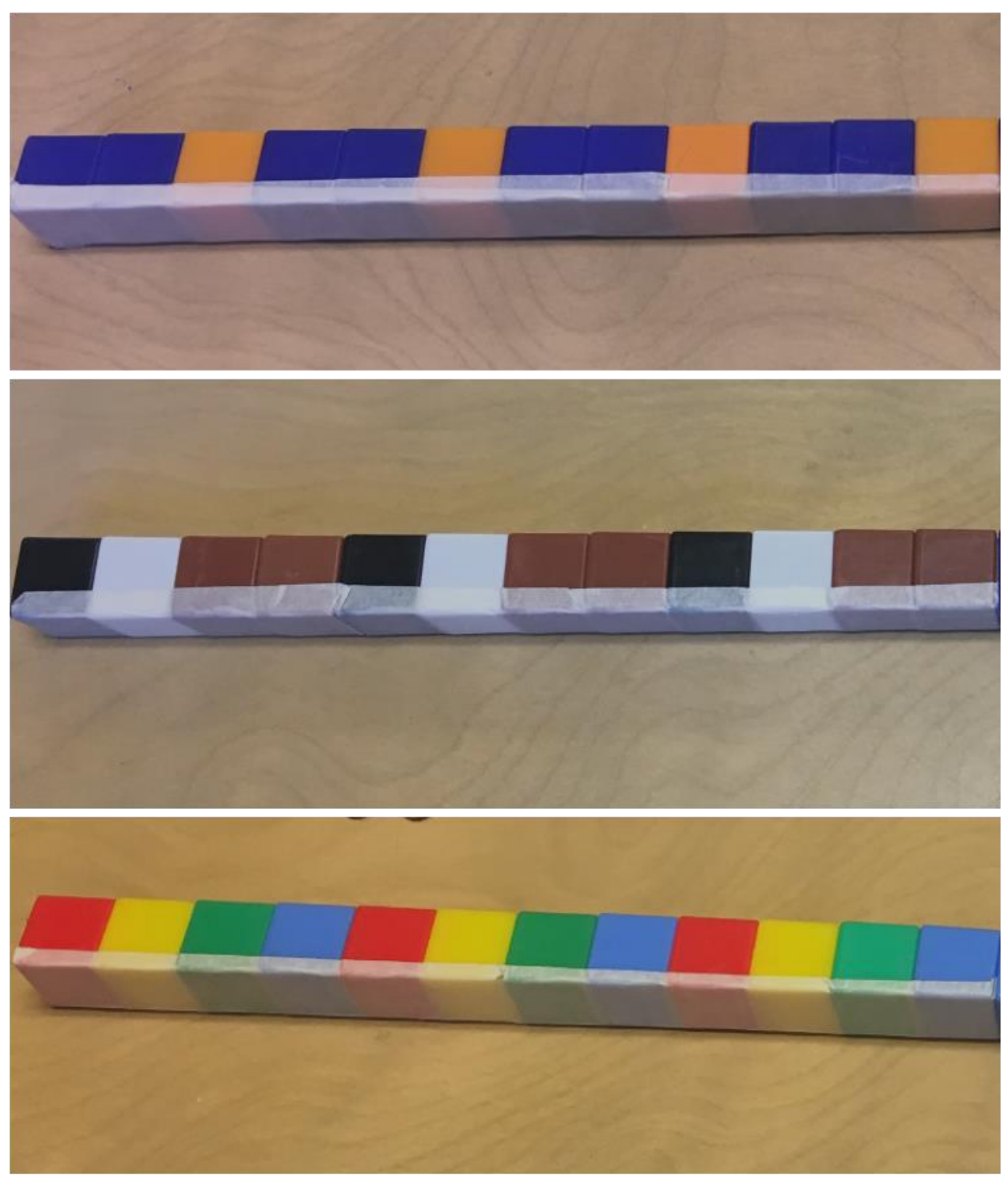

Figure 3. Model $A A B, A B C C$, \& $A B C D$ patterns used in each task

Extension task. For the extension task, children were provided a box of interlocking blocks that contained enough blocks (4 to 6 of each color) to 
permit extending a pattern for four more cores. The task was introduced at pretest with a practice trial involving an $\mathrm{AB}$ pattern and the instructions: "In the Keep Going Game, I'll show you a pattern using interlocking blocks like this [the child was shown White-Red-White-Red-White-Red interlocking cubes]. Use these cubes [tester pointed to the box] to make the pattern "keep going - to make the pattern longer." If the child did not respond or had difficulty, the tester helped by adding a white and then a red cube and encouraged the child to make the pattern longer. If a child added only one white and one red, the tester said: "Can you keep going?" A correct response to a test trial ( 1 point) entailed extending the pattern at least one full core unit of the pattern without errors (using only complete examples of the core). Partial credit ( 0.5 points) was granted if the child produces at least one full core unit of the pattern and part of another.

Core identification. For the core-identification task, children were shown a pattern in the same order as the extension task and instructed: "Use these cubes [the tester pointed to the box] to see what part of the pattern [a tester draw her finger along the length of the interlocking cubes forming the pattern] keeps repeating." If need be, the tester asked, "What is the smallest part of the pattern that happens again, and again, and again to make the pattern?" A correct response (accurately representing the unit core with interlocking blocks) was scored 1 point. Partial credit (0.5 points) was awarded if a child could point out the core but could not represent it accurately with interlocking blocks - in effect duplicate or extend the core. For example, on the posttest, one child identified the core of an ABB pattern (pointed out blue-blue-orange) but represented the elements out of order (as orange-blue-blue). Another child identified the core of an ABCD pattern (pointed out red-yellow-green-blue) but represented it incompletely (as redyellow-green).

\section{Design}

An experimental pretest-posttest design was used. A pretest served to identify a child's developmental level, identify eligible participants, and to establish baseline patterning knowledge. Only children who were unsuccessful (scored less than 2 of a possible 3 ) on both the extension task (Level-2b and -2c) and core-identification (Level-4) task and, thus, logically were at Level 1 or, at best, Level $2 b$ were included in the study. Participants were randomly assigned to an intervention. Two weeks after the last intervention session, a delayed posttest was administered involving patterns not used in the training to gauge retention and transfer. Note that random assignment controls for a variety of confounding factors including history, testing, and selection effects. Moreover, using the same activities for the HLTLike and non-HLT instruction controls for the impact of content coverage, materials used, and dosage. 


\section{Analyses}

Data were analyzed quantitatively and qualitatively. As the assumptions of parametric tests were not met, non-parametric tests were used. The Wilcoxon signed-rank test for dependent samples was used to gauge each group's pretest-posttest growth on the main dependent variable (core identification) and the secondary measure (extension). The Mann-Whitney U test was used to compare the impact of (a) the interventions (instructional order) and (b) age on pretest-posttest gains for each measure. In addition to checking for statistical significance, effect size was checked for statistical magnitude of the effect and practical significance (Lipsey et al., 2012). The basis of the qualitative analysis was the extensive notes taken on the participants' reaction to each lesson and progress.

\section{Results}

\section{Quantitative Analyses}

Table 3 summarizes the pretest and posttest results for the primary dependent variable (core identification) and the secondary dependent variable (pattern extension) for each intervention. The pretest results reflected the selection criterion. All but one non-HLT child (who was correct on only a single trial) had no success on the core-identification task (i.e., were incorrect on all three trials), and children in both groups had little or no success on the extension task. At pretest, the two groups did not differ significantly on either the core-identification task $(U=28, z$-score $=-0.368, p=.711,2$-tailed MannWhitney Test $)$ or the extension task $(U=29.5, z$-score $=-0.210, p=.837,2$ tailed Mann-Whitney Test). Both the HLT-Like and non-HLT participants exhibited significant pretest-posttest improvement on the core-identification task ( $W=0$ and 1 , respectively; $p<.05$ for both, 1-tailed Wilcoxon SignedRanks Test; $\eta^{2}=12.706$ and 12.355 , respectively) and the extension task (for both: $W=0, p<.05$, 1-tailed Wilcoxon Signed-Ranks Test, and $\eta^{2}=0.596$ ). Indeed, for the primary dependent measure, five of eight HLT-Like and four of eight non-HLT children were successful on at least a majority of the posttest trials. The comparable figures for the secondary measure were six and five, respectively.

Impact of order. The HLT-Like participants' pretest-posttest gains for core-identification was 0.375 correct trials greater than that by the non-HLT group. As indicated by effect size $(d=0.238)$, this difference was substantial, though not significant $(U=27.5, z$-score $=0.4205,1$-tailed $p=.334)$. As expected, there was neither a significant nor a substantial effect on the extension task $(U=31, z$-score $=0.053,1$-tailed $p=.480 ; d=0.053)$. 
Table 3

\section{Pretest and Mean (S.D.) for Each Intervention Group for the Primary Dependent Variable (Core Identification) and the Secondary Measure (Extension)}

\begin{tabular}{lllll}
\hline & \multicolumn{2}{c}{$\begin{array}{l}\text { Core- } \\
\text { Identification } \\
\text { Task }\end{array}$} & \multicolumn{1}{c}{ Extension Task } \\
Group & Pretest & Posttest & Pretest & Posttest \\
\hline HLT-Like & 0 & 1.8130 & 0.313 & 2.000 \\
& $(0)$ & $(0.923)$ & $(0.594)$ & $(1.069)$ \\
\hline Non-HLT & 0.125 & 1.500 & & \\
& $(0.333)$ & $(1.415)$ & 0.375 & 1.938 \\
& & & $(0.518)$ & $(1.374)$ \\
\hline
\end{tabular}

Note. Scores for each task could range from 0 to 3 .

Impact of age. Five results converge to indicate that age is a key factor in whether children benefit from patterning instruction.

- Regarding overall success, 4-year-olds exhibited more than twice the pretest-posttest gains than did the 3-year-olds on the core-identification (Level-4) task (mean gain of 2.111 versus $1.000, U=15, z$-score $=1.694$, 1 -tailed $p=.046$, a large effect size of $d=0.971$ ) and the extension (Level-2) task (mean gain of 2.278 versus $0.786, U=5, z$-score $=2.752$, 1-tailed $p=.006$, a very large effect size of $d=1.967$ ).

- Regarding consistent success, whereas seven of nine 4-year-olds achieved success on a majority of the trials (i.e., scored $\geq 2$ of 3 points) for the coreidentification task at posttest, only two of seven 3-year-olds did so (Fisher Exact $2 \times 2$ Test value $=0.1262 ; 1$-tailed $p=.072$; odds ratio $=8.75$ ) Similarly, whereas eight had success on a majority of the trials (i.e., scored $\geq 2$ of 3 points) for the extension task at posttest, only one 3 -year-olds benefitted from patterning instruction (Fisher Exact $2 \times 2$ Test value $=$ 0.0034 ; 1 -tailed $p=.006$; odds ratio $=56$ ). Indeed, all nine children who were successful on the core-identification task at posttest were 3.75 years of age or older (Fisher Exact Test value $=0.0192 ; 1$-tailed $p=.019$; odds ratio $=$ infinite). Similarly, all 10 children who were successful on the extension task at posttest were 3.75 years of age or older (Fisher Exact Test value $=0.0927$; 1 -tailed $p=.003$; odds ratio $=$ infinite). For both analyses for each task, note that an odds ratio of 4 or more is relatively strong and unlikely to be explained by another unmeasured variable.

- Four of the five children who were excluded from the study because they were untestable at pretest (and unlikely to benefit from the patterning instruction) were less than 3.75-years old. 
- Two of the three children who excluded from the study because they had already at achieved at least some success at Level 2c (were successful on most of the extension trials at pretest) were 4-year-olds. The third was 3.53 years of age.

- The one child in the study who quit after two training sessions was a 3.5year-old.

Impact of developmental level. Two HLT-like and three non-HLT participants who exhibited partial Level-2 competence at pretest all achieved success on the core-identification (Level-4) task at posttest. In contrast, among participants who were at Level 1 at pretest, half of the six HLT-like participants and only one of the five non-HLT children did so. Initial pretest level, then, made a significant difference in achieving Level-4 performance at posttest (Fisher Exact $2 \times 2$ Test value $=0.0337$; 1 -tailed $p=.029$; odds ratio $=$ $2.75)$. Note that the odds ratio indicates that core-identification success as a result of patterning instruction is 2.75 times more likely for Level- 2 children than for Level-1 children.

\section{Qualitative Analyses}

Most children in both the HLT-Like and Non-HLT groups appeared to benefit from their training. For example, as Figure 4 illustrates, most children in both interventions were able to create their own $\mathrm{ABB}$ and $\mathrm{ABC}$ patterns- $\mathrm{a}$ Level 3 or pattern-generalizer activity. On one hand, though, some HLT-Like children appeared somewhat restless with the pace of instruction and perhaps might have benefitted from a faster pace or the extra challenges posed by the non-HLT intervention. On the other hand, some children in the non-HLT intervention appeared overwhelmed or confused by the multiple new demands of their instruction and may have benefitted from the slower pace of the HLTLike Intervention.

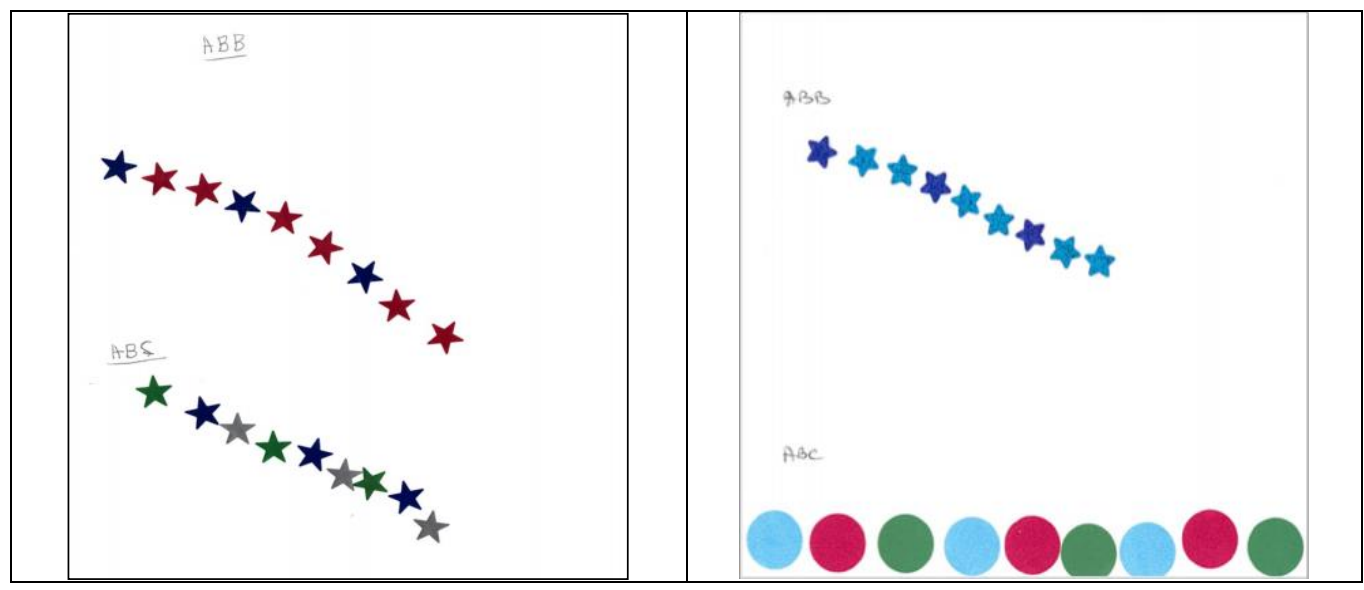

Figure 4. Sample responses to the Session 10 activity: create an $A B B$ and $A B C$ pattern (on the left, an HLT-Like child; on the right, a Non-HLT child). 
Although logically an aspect of Level 3 (translating a pattern into a different format), children in both conditions quickly learned to translate repeating patterns into letters (e.g., translating $\mathbf{0 0 \mathbf { 0 0 }}$ into the plastic alphabet letters: $\mathrm{ABABAB}$ ). In contrast, they struggled mightily with translating patterns into different materials (e.g., translating the circle-squarecircle-square-circle-square pattern depicted above into triangles-hexagontriangle-hexagon-triangle-hexagon or - in a few cases - even a circle-square repeating pattern involving different colors; cf. Fyfe et al., 2015).

\section{Conclusions}

As demonstrated by transfer on core-identification and extension tasks involving novel (unpracticed) and developmentally challenging patterns, participants in both the HLT-like and non-HLT interventions appeared to benefit significantly and, as measured by effect size, substantially from targeted patterning instruction. In addition to transfer, another indication of enduring meaningful learning (as opposed to transitory knowledge learned by rote) is that these gains were found two weeks after the training. Although it could be argued that such gains are merely due to a nuance variable such as a testing effect, history effect, or regression to the mean, a larger scale followup RCT likewise found that a similar HLT-like or non-HLT intervention had a significant and substantial impact on Level-4 and -2 patterning knowledge over a business-as-usual control condition (Yilmaz, Baroody, Clements, Sarama, \& Sahin, 2020a).

\section{Value of HLTs}

The effect size found in the present experiment suggested that, compared to the non-HLT training, patterning instruction based on an HLT had a small beneficial impact on fostering core identification (Level 4 in Table 1). As predicted, treatment did not have a substantial impact on extension (Level-2) performance, because all participants were ready for this instruction when presented.

However, as half the non-HLT participants also achieved Level 4 at posttest, clearly following the HLT was not necessary for helping all children become core identifiers. That is, the present results indicate that one method may not suit all children. For example, although some children in the nonHLT condition appeared to thrive with the challenge of learning a number of new ideas more or less simultaneously, some seemed overwhelmed. It may not be coincidental that the only child who refused further training (after two sessions) was in the non-HLT condition.

Unlike other HLT research (Baroody et al., under review; Clements et al., 2019, 2020a, 2020b), why did the HLT-like patterning intervention not have a significant or more substantial impact than the non-HLT intervention? 
One possibility is that the small sample size provided insufficient power to detect a real difference. However, preliminary analyses of a follow-up RCT with twice the number of participants per group also yielded a non-significant difference (Yimaz et al., 2020a).

A second possibility is that a different sampling of children might better benefit from the patterning HLT. For example, as discussed further in the next section titled "Other Instructional Implications," a sample consisting largely or exclusively of Level-1 children might provide a starker contrast of the value of a developmentally ordered approach.

A third possibility is that Level 2 of the patterning HLT is a facilitative, not a necessary, condition for achieving core identification (Level 4). This would also help explain why some non-HLT participants achieved success with the target level in the present study but not in, for example, Baroody et al.'s (under review) study, where a lower level of cardinality knowledge was a developmental prerequisite (a necessary condition) for a higher level. This possibility is also consistent with Rittle-Johnson et al.'s (2015) view that Levels 2a, 2b, 3 and 4 form a "construct map" for repeating patterns - a probabilistic continuum of knowledge rather than distinct phases of knowledge.

A fourth possibility, which is consistent with the third just discussed, is that Level-2 children implicitly attend to the core when, say, extending a pattern and only later construct the explicit knowledge that permits success on the core-identification task used to assess Level 4 (see Yilmaz, Baroody, \& Sahin, 2020b; cf. Rittle-Johnson et al., 2015). That is, experiences constructing Level 2 implicitly draws attention to the core and can facilitate explicit attention to the core during Level-4 training whether conducted simultaneously or afterward.

A fifth possibility is that the positive impact of the HLT-based instruction may be greater outside of a controlled sequence of activities such as used in the present experiment. To equate coverage and dosage, HLT-Like participants were given a fixed sequence of activities, regardless of their progress. In contrast, HLTs are recommended as resources to support more flexible instruction based on formative assessment (Clements \& Sarama, 2014; Frye et al., 2013). That is, the use of HLTs typically involves remaining at a level until it is attained and immediately moving to a higher level once attained. This probably would have helped the three HLT-Like participants who made little progress (scored 0.5 or 1 points at posttest) on the coreidentification task. Formative assessment and adaptive instruction also might have alleviated the frustration experienced by some of the successful HLTLike participants with the pace of their instruction. However, it does not explain why some non-HLT participants were able to achieve success on the core-identification task at posttest. 


\section{Other Instructional Implications}

The study's main practical and scientific benefit may be suggested revisions about when specific patterning competencies are taught. Four key instructional implications, which bear further study, are discussed.

Age. Most 4-year-olds, but not most 3-year-olds, may benefit from extension (Level-2) and core-identification (Level-4) training. Moreover, as only the two eldest 3-year-olds-age 3-years and 9 months and 3-years and 11-months-benefitted from (HLT-Like) patterning instruction, about 3.75 years of age may be a critical age below which such instruction may be (largely) fruitless. Further research is needed to confirm these conjectures. Moreover, if confirmed, additional research is needed to identify the reason(s) for the age difference or critical age. Is readiness for patterning instruction tied to social maturation or the maturation of general cognitive abilities such as executive function? Might it have more to do with - as hinted by the present results and discussed next-experience and the patterning level a child achieves informally?

Letter use. Using letters to label the elements of a pattern seems to be a distinct form of translating patterns that can be introduced to children early in the patterning trajectory to foster Level-2 competencies. More specifically, whereas labeling the core with letters appears useful in promoting patterntranslation (Level-3 in Table 1) thinking (Fyfe et al., 2015), labeling the elements of an $\mathrm{AB}$ pattern and more complex repeating patterns may foster the ability to extend such patterns - achieving Level $2 \mathrm{~b}$ and $2 \mathrm{c}$, respectively. Double-naming of a pattern by the teacher (e.g., "red-blue, red-blue, redblue...let's say it with letters now: ABABAB...") may be interpreted by children as an alternative linguistic description, which is a common experience. In contrast, translating a pattern into a new physical medium involves distracting perceptual characteristics. In brief, it appears that the Building Blocks curriculum (Clements \& Sarama, 2013) is justified, then, in using letters to label the elements of a pattern in Level-2 instruction.

Pattern translation. Other aspects of the current Level 3 (translating a pattern into different objects) may be more challenging and facilitated by an explicit understanding the concept of a core unit. That is, contrary to existing developmental evidence (Rittle-Johnson et al., 2013, 2015), Levels 3 and 4 in Table 1 may need to be reversed. This conjecture is consistent not only with our informal observations but with Fyfe et al.'s (2015) finding that using letters to identify unit cores was efficacious in promoting the ability to translate a pattern into different objects. Although an implicit consideration of unit may naturally help some children to translate a repeating pattern into different materials, systematic instruction that first involves using letters to label the elements of a pattern (Level-2) and then the core of a pattern may provide a better basis for the majority of children to tackle this challenging task. 
Starting level. The results regarding starting level illustrate the adage that prior knowledge typically is the most important factor in predicting new meaningful learning and the assumption of HLTs that instruction one level above a child's current level is most efficacious. Indeed, the starting-level results (and the non-significant impact of order on achieving core identification) make even more sense in light of the revised HLT. Participants who started with some pattern-extension (Level-2) competence at pretest were successful at core identification regardless of intervention. A child who started at Level $2 \mathrm{~b}$ (pattern extension of AB patterns) needed to achieve but a single sublevel (Level 2c) to be one level below the target of instruction, core identification (the new Level 3). As letters seem useful in labeling pattern elements at Level 2 and in promoting extension skills, the non-HLT participants actually had advantage over HLT-Like participants who did not translate patterns into letters after their Level-2 instruction. In contrast, children who started at Level 1 were three sublevels below the target. Though further research is needed, the data trend suggested that such children were more likely to achieve the target if instruction was sequenced developmentally (i.e., proceeded more gradually from Sublevel $2 a$, to $2 b$, to $2 c$, and then 3 ).

\section{Summary}

A small effect size indicated that an HLT-based intervention was somewhat more effective in promoting the target knowledge (core identification) than an intervention that involved the same activities but not developmentally ordered. One reason for why the HLT-based may not have had a bigger impact than other HLT research include the nature of the developmental relations among levels: Lower pattern levels involve a facilitative relation with high levels, whereas with other domains studied, lower levels entail a necessary condition for higher levels. The impact of ordered instruction appeared to matter more for children starting lower on the HLT than those whose starting level was closer to the target. Patterning instruction of any type was significantly more efficacious with 4-year-olds than 3-year-olds and especially those younger than 3.75 years of age. Although labeling the elements of a repeating pattern with letters would seem to be an advanced pattern-translation skill, participants found it much easier to do than translating a pattern into other objects. Translating a pattern into different objects seems even more challenging than core identification, and these two levels may need to be reversed.

\section{References}

Baratta-Lorton, M. (1972). Workjobs: Activity-centered learning for early childhood. Menlo Park, CA: Addison-Wesley.

Baroody, A. J. (1993). Problem solving, reasoning, and communicating, Grades K-8: Helping children think mathematically. New York, NY: 
Merrill-MacMillan.

Baroody, A. J. (2016). Using number and arithmetic instruction as a basis for fostering mathematical reasoning. In M. T. Battista (Ed.), Reasoning and sense making in the mathematics classroom: Pre-K-Grade 2 (pp. 27-69). Reston, VA: National Council of Teachers of Mathematics.

Baroody, A. J., Clements, D. H., \& Sarama, J. (under review.) Does use of a hypothetical learning trajectory facilitate the learning of countingbased cardinal-number concepts?

Bennett, J., \& Müller, U. (2010). The development of flexibility and abstraction in preschool children. Merrill-Palmer Quarterly, 56, 455473. https://www.jstor.org/stable/23097951

Burgoyne, K., Witteveen, K., Tolan, A., Malone, S., \& Hulme, C. (2017). Pattern understanding: Relationships with arithmetic and reading development. Child Development Perspectives,

11, 239-244. https//doi.org/10.1111/cdep.12240

Butterfield, B., Forrester, P., Mccallum, F., \& Chinnappan, M. (2013). Use of learning trajectories to examine pre-service teachers' mathematics knowledge for teaching area and perimeter. In V. Steinle, L. Ball, \& C. Bardini (Eds.), Mathematics education: Yesterday, today, and tomorrow (Proceedings of the $36^{\text {th }}$ annual conference of the Mathematics Education Research Group of Australia, pp. 122-129), Melbourne, VIC: MERGA.

Clements, D. H., \& Sarama, J. (2008). Experimental evaluation of the effects of a research-based preschool mathematics curriculum. American Educational Research Journal, 45(2), 443-494.

https://doi.org/10.3102/0002831207312908

Clements, D. H., \& Sarama, J. (2013). Building Blocks, Volumes 1 and 2. Columbus, OH: McGraw-Hill (2 volumes, Teacher's Edition, Teacher's Resource Guide, Assessment Guide).

Clements, D. H., \& Sarama, J. (2014). Learning and teaching early math: The learning trajectories approach. New York: Routledge.

Clements, D. H., Sarama, J., \& DiBiase, A.-M. (2004). Engaging young children in mathematics: Standards for early childhood mathematics education. Mahwah, NJ: Erlbaum.

Clements, D. H., Sarama, J., Baroody, A. J., Joswick, C. (2020a). Efficacy of a learning trajectory approach compared to a teach-to-target approach for addition and subtraction. ZDM Mathematics Education, 52(4) 637649. https://doi.org/10.1007/s11858-019-01122-z

Clements, D. H., Sarama, J., Baroody, A. J., Joswick, C., Wolfe, C. (2019). Evaluating the efficacy of a learning trajectory for early shape composition. American Educational Research Journal, 56(6), 25092530. https://doi.org/10.3102/0002831219842788

Clements, D. H., Sarama, J., Baroody, A. J., Kutaka, T. S., Chernyavskiy, P., Joswick, C., Cong, M., \& Joseph, E. (2020b). Comparing the efficacy 
of early arithmetic instruction based on a learning trajectory and teaching-to-a-target. Journal of Educational Psychology.

https://doi.org/10.1037/edu0000633

Collins, M. A., \& Laski, E. V. (2015). Preschoolers' strategies for solving visual pattern tasks. Early Childhood Research Quarterly, 32, 204214. https//doi.org/10.1016/j.ecresq.2015.04.004

Frye, D., Baroody, A. J., Burchinal, M. R., Carver, S., Jordan, N. C., \& McDowell, J. (2013). Teaching math to young children: A practice guide. Washington, DC: U.S. Department of Education, Institute of Education Sciences, National Center for Education Evaluation and Regional Assistance (NCEE).

Fuson, K. C. (2004). Pre-K to grade 2 goals and standards: Achieving 21st century mastery for all. In D. H. Clements, J. Sarama, \& A.-M. DiBiase (Eds.), Engaging young children in mathematics: Standards for early childhood mathematics education (pp. 105-148). Mahwah, NJ: Erlbaum.

Fyfe, E. R., McNeil, N. M., \& Rittle-Johnson, B. (2015). Easy as ABCABC: Abstract language facilitates performance on a concrete patterning task. Child development, 86(3), 927-935. https://doi.org/10.1111/cdev.12331

Kidd, J. K., Pasnak, R., Gadzichowski, K. M., Gallington, D. A., McKnight, P., Boyer, C. E., \& Carlson, A. (2014). Instructing first-grade children on patterning improves reading and mathematics. Early Education \& Development, 25, 134-151.

https://doi.org/10.1080/10409289.2013.794448

Lipsey, M. W., Puzio, K., Yun, C., Hebert, M. A., Steinka-Fry, K., Cole, M. W., . . . Busick, M. D. (2012). Translating the statistical representation of the effects of education interventions into more readily interpretable forms. Washington, DC: IES National Center for Special Education Research, Institute of Education Sciences.

Lobato, J., \& Walters, C. D. (2017). A taxonomy of approaches to learning trajectories and progressions. In J. Cai (Ed.), Compendium for research in mathematics education (pp. 74-101). Reston, VA: National Council of Teachers of Mathematics.

Maloney, A. P., Confrey, J., \& Nguyen, K. H. (Eds.). (2014). Learning over time: Learning trajectories in mathematics education. New York, NY: Information Age Publishing.

Miller, M. R., Rittle-Johnson, B., Loehr, A. L., \& Fyfe, E. R. (2016). The influence of relational knowledge and executive function on preschoolers' repeating pattern knowledge. Journal of Cognition and Development, 17, 85-104. https//doi.org/10.1080/15248372.2015.1023307

National Council of Teachers of Mathematics. (2000). Principles and standards for school mathematics. Reston, VA: Author. 
National Research Council. (2009). Mathematics learning in early childhood: Paths toward excellence and equity. Washington, DC: National Academy Press.

NGA/CCSSO. (2010). Common core state standards. Washington, DC: National Governors Association Center for Best Practices, Council of Chief State School Officers.

Papic, M. M., Mulligan, J. T., \& Mitchelmore, M C. (2011). Assessing the development of preschoolers' mathematical patterning. Journal for Research in Mathematics Education, 42, 237-268. https//doi.org/10.5951/jresematheduc.42.3.0237

Rittle-Johnson, B., Fyfe, E. R., Loehr, A. L., \& Miller, M. R. (2015). Beyond numeracy in preschool: Adding patterns to the equation. Early

Childhood Research Quarterly, 31, 101-112. https//doi.org/10.1016/j.ecresq.2015.01.005

Rittle-Johnson, B., Fyfe, E. R., McLean, L. E., \& McEldoon, K. L. (2013). Emerging understanding of patterning in 4-year-olds. Journal of Cognition and Development, 14(3), 376-396.

https://doi.org/10.1080/15248372.2012.689897

Sarama, J., \& Clements, D. H. (2009). Early childhood mathematics education research: Learning trajectories for young children. New York, NY: Routledge.

Simon, M. A. (1995). Reconstructing mathematics pedagogy from a constructivist perspective. Journal for Research in Mathematics Education, 26(2), 114-145.

Steen, L. A. (1990). Pattern. In L. A. Steen (Ed.), On the shoulders of giants: New approaches to numeracy (pp. 1-10). Washington, D.C.: National Academy Press.

Wu, H.-H. (2011). Understanding numbers in elementary school mathematics. Providence, RI: American Mathematical Society. http://dx.doi .org/10.1090/mbk/079

Yilmaz, N., Baroody, A. J., Clements, D. H., Sarama, J., \& Sahin, V. (2020a, April). Does a learning trajectory facilitate learning to recognize the core unit of a repeating pattern. Roundtable Session titled, Exploring Cognitive Processes in Mathematics, American Educational Research Association Annual Meeting, San Francisco, CA. http://tinyurl.com/ud8ayg8 (Conference Canceled)

Yilmaz, N., Baroody, A. J., \& Sahin, V. (2020b, April). What do eye-tracking data say about the cognitive mechanisms underlying the pattern extension skills of young children? Poster presented at the Stanford Educational Data Science Conference, Stanford, CA. 


\section{Authors:}

Arthur J. Baroody is a Professor Emeritus of Curriculum \& Instruction, College of Education, University of Illinois at Urbana-Champaign, USA. His research focuses on the teaching and learning of early number, counting, and arithmetic concepts and skills. He is the co-author of the Test of Early Mathematics Ability ( $3^{\text {rd }}$ edition; published 2003 by Pro-Ed) and the 2013 What Works Clearinghouse Teaching math to young children: A practice guide, published by the U.S. Department of Education <http://ies.ed.gov/ncee/wwc/practiceguide.aspx?sid=18>). https://www.researchgate.net/profile/Arthur-Baroody

Nursel Yilmaz is a Research Assistant Professor at Osmaniye Korkut Ata University, Turkey. She recently received a Ph.D. from Middle East Technical University, where she focused on designing and developing effective educational practices to support young children's cognitive development and using technological tools to understand cognitive mechanisms underlying children's learning. She has extensive experiences in conducting educational research using both quantitative and qualitative research methods as well as innovative research designs. Most recently, she received the Emerging Researcher Award by European Educational Research Association (EERA) and the International Scholars Award by American Educational Research Association (AERA).

Douglas H. Clements is a Distinguished University Professor and Kennedy Endowed Chair in Early Childhood Learning at the University of Denver, Colorado, U.S.A. Clements has published over 166 refereed research studies, 27 books, 100 chapters, and 300 additional works on the learning and teaching of early mathematics; computer applications; creating, using, and evaluating research-based curricula; and taking interventions to scale, mostly with colleague and wife Julie Sarama.

http://du.academia.edu/DouglasClements, http://www.researchgate.net/profile/ Douglas_Clements

Julie Sarama is Kennedy Endowed Chair in Innovative Learning Technologies and Distinguished University Professor at the University of Denver. She has taught high school mathematics, computer science, middle school gifted mathematics and early childhood mathematics. She directs projects funded by the NSF and IES and has authored over 77 refereed articles, 6 books, 55 chapters, and over 80 additional publications. Her interests include development of concepts and competencies, implementation and scale-up of interventions, and professional development models' influence on student learning. https://www.researchgate.net/profile/Julie_Sarama 